\title{
The Effect of Novel Binary Accelerator System on Properties of Vulcanized Natural Rubber
}

\author{
Moez Kamoun, Abdallah Nassour, and Nelles Michael \\ Department of Waste Management, Faculty of Agricultural and Environmental Sciences, 18051 Rostock, Germany \\ Correspondence should be addressed to Moez Kamoun, kamoun.moez2@gmail.com
}

Received 11 July 2009; Accepted 19 December 2009

Recommended by Pearl Lee-Sullivan

\begin{abstract}
The mechanical properties, curing characteristics, and swelling behaviour of vulcanized natural rubber with a novel binary accelerator system are investigated. Results indicate that the mechanical properties were improved. Crosslinking density of vulcanized natural rubber was measured by equilibrium swelling method. As a result, the new binary accelerator was found to be able to improve both cure rate and crosslinking density. Using the numerical analysis of test interaction between binary accelerator and operational modelling of vulcanization-factors experiments, it can be concluded that the interaction (Cystine, N-cyclohexyl2-benzothiazyl sulfenamide) was significant and the optimum value of binary accelerator was suggested, respectively, at levels 0 and +1 .
\end{abstract}

Copyright (C) 2009 Moez Kamoun et al. This is an open access article distributed under the Creative Commons Attribution License, which permits unrestricted use, distribution, and reproduction in any medium, provided the original work is properly cited.

\section{Introduction}

The problem of vulcanized rubber is of a high importance nowadays. According to the International Rubber Study Group, in that year to March 2009, the world consumption of natural rubber and synthetic rubber reached 21.1 million tons [1]. The initial major elastometric technology advancement was the consecutive discovery of vulcanization by Goodyear and Hancock [2]. Through the vulcanization of rubber compounds and in the option of rubber processing, small quantities of chemicals, which belong to a group called accelerators, were used. The selection of accelerator in sulfur vulcanization determines the category of network structure produced and, consequently, the specific material properties. The chosen accelerator affects the cure rate and scorch safety, as well as the number and average length of the crosslinks formed.

Investigation on rubber vulcanization has gained vast thrust with the introduction of a new class of compounds called binary accelerators [3]. Because of the reduced time required for curing and production of improved end-use products, the study of new accelerator systems is still an inexhaustible and interesting topic of research. Although the mechanism of vulcanization is still open for discussion, the use of different curatives has gained importance, depending on their performance.
Different studies were conducted on binary accelerator systems via different approaches [3-5]. The objective of the present study is to evaluate the effect of a new binary system based on Cystine (Cys) and N-cyclohexyl-2-benzothiazyl sulfenamide (CBS) in conventional vulcanization system of natural rubber (NR). Investigations were made on the rheological and mechanical properties of the vulcanizate cured with the binary system.

\section{Experimental Method}

2.1. Materials. NR (RSS 3) was purchased from the Teck Bee Hang, and the CBS accelerator (Vulcacit, CZ) was obtained from Bayer AG. Other rubber chemicals like zinc oxide, stearic acid, and sulfur were all commercial grades. Cystine (Cys) was purchased from Gal-Pharma, Ltd. Cystine was the amino aciddimer produced when a pair of cysteine molecules were joined by a disulfide bond. It is described by the formula $\left(\mathrm{SCH}_{2} \mathrm{CH}\left(\mathrm{NH}_{2}\right) \mathrm{CO}_{2} \mathrm{H}\right)_{2}[6]$.

2.2. Binary Accelerator System (Cys, CBS). The behaviour of amino acids as ligand toward metal cation such as zinc in the formulation of styrene butadiene rubber (SBR 1509) has been the subject of a previous study [7]. Among amino 
TABLE 1: Formulations for rubber compounds.

\begin{tabular}{lccccc}
\hline Materials $\left(\mathrm{phr}^{\mathrm{a}}\right)$ & $M 0$ & $M 1$ & $M 2$ & $M 3$ & $M 4$ \\
\hline Natural Rubber & 100 & 100 & 100 & 100 & 100 \\
Zinc oxide & 5.00 & 5.00 & 5.00 & 5.00 & 5.00 \\
Stearic acid & 2.00 & 2.00 & 2.00 & 2.00 & 2.00 \\
CBS & 0.80 & 0.80 & 0.80 & 0.80 & 0.80 \\
Cystine (Cys) & 0.00 & 0.25 & 0.50 & 0.75 & 1.00 \\
Sulphur & 2.50 & 2.50 & 2.50 & 2.50 & 2.50 \\
\hline
\end{tabular}

${ }^{a}$ phr: parts per hundred parts rubber.

acids containing sulfur atoms, Cystine has been the most commonly studied [8].

Cystine (Cys) has two carboxylic groups quite far from each other. The binary system based on (Cys, CBS) may involve complex formation with zinc cation and stearic acid, which can then be bound to each carboxylic group without influence on the other carboxyl behaviour<smiles>NC(CSSCC(N)C(=O)O)C(=O)O</smiles>

$\mathrm{R}:-\mathrm{CH}_{2} \mathrm{CH}\left(\mathrm{NH}_{2}\right) \mathrm{COOH}$

Cys: R-S-S-R

One way to illustrate this effect is to measure the mechanical or physical properties as a function of the accelerator ratio and correlate the optimum property with the complex formation.

2.3. Compounding and Testing. The mixture of natural rubber (NR) was carried out on a two-roll open mill at $70^{\circ} \mathrm{C}$, according to ASTM D 3182. The formulations of the mixes are given in Table 1. The mixes were cured in a hydraulic press at $150^{\circ} \mathrm{C}$ for the optimum cure time. The tensile properties and tear resistance of the compounds were measured on an Instron 4465 Universal, tensile testing machine at a crosshead speed of $500 \mathrm{~mm} / \mathrm{min}$ according to ASTM D 412 and ASTM D 624, respectively.

The hardness of the cured compound was measured according to ASTM D 2240 using a Shore A type durometer. The compression set of the compounds was measured according to ASTM D 396. The resilience of the samples was measured using a Dunlop Tripsometer according to ASTM D 2632.

2.4. Vulcanization Characteristics. The vulcanization characteristics of the NR compounds studied were determined by Monsanto 100S anoscillating disk rheometer. Scorch time $\left(t_{\mathrm{sc}}\right)$ was taken as the time at which the rheometer torque raised two units from the minimum torque. Optimum cure time $\left(t_{90}\right)$ was taken as the time at which the rheometer torque increased to $90 \%$ of the total torque change following curing of rubber [9].
2.5. Crosslinking Density. The crosslinking density of NR compounds was determined by the equilibrium swelling method. A sample weighing about $0.2 \mathrm{~g}$ was cut from the compression-moulded rubber sample. The sample was soaked in pure benzene at room temperature to allow the swelling to reach diffusion equilibrium [10]. After 5 days, swelling was stopped; at the end of this period, the test piece was taken out, the adhered liquid was rapidly removed by blotting with filter paper, and the swollen weight was measured immediately. The samples were dried in a vacuum to constant weight, and the desorbed weight was taken. The swelling ratio is defined as

$$
R=\frac{\left(m_{s}-m_{0}\right)}{m_{0}} .
$$

Respectively, $m_{0}$ is the weight of the test piece before swelling and $m_{s}$ is the weight of the swollen test piece after time $t$ of immersion. The swelling ratio is a direct measurement of the degree of crosslinking: the smaller the ratio is, the higher the degree of crosslinking obtained. The crosslinking density [11, 12] was determined according to the relation

$$
\gamma=\frac{\left[\ln \left(1-\psi_{r}\right)+\psi_{r}+\chi \psi_{r}\right]}{V_{S}\left(\psi_{r}^{1 / 2}-\psi_{r} / 2\right)} .
$$

Respectively, $V_{S}$ was the molar volume of benzene that is $89.4 \mathrm{~cm}^{3} / \mathrm{mol}$ [10]. $\chi$ was a parameter characteristic of interaction between the rubber network and the swelling. For NR-Benzene, the value of $\chi$ could be taken as a constant (0.425) [10]. $\psi_{r}$ was the volume friction of rubber in the swollen NR vulcanizate, which could be calculated according to the following relation:

$$
\psi_{r}=\frac{\left[\left(m_{d}-m_{0} \omega\right) / \rho_{s}\right]}{\left[\left(m_{d}-m_{0} \omega\right) / \rho_{r}+\left(m_{s}-m_{d}\right) / \rho_{s}\right]} .
$$

Respectively, $m_{d}$ was the mass of the test specimen after drying for 5 days at room temperature. $\rho_{r}$ was the density of NR which was taken as $0.965 \mathrm{~g} / \mathrm{cm}^{3} . \rho_{s}$ was the density of solvent that was $0.865 \mathrm{~g} / \mathrm{cm}^{3}$ for benzene. $\omega$ was the mass friction of the filler and zinc oxide in the test specimen.

\section{Results and Discussion}

3.1. Mechanical Properties. The mechanical properties of the vulcanizate are given in Table 2 . The strength increases with the addition of Cystine. A maximum strength is shown by M2 at a concentration of $0.5 \mathrm{phr}$ of Cystine. This may be possible because of the increase in crosslink density. The modulus values at $300 \%$ elongation are also given in Table 2. It is found that, as the concentration of Cystine increases, the modulus values also increase. The maximum modulus is shown by mixes $M 2$ which have Cystine concentrations of $0.5 \mathrm{phr}$.

The tensile strength first increases and then decreases with the Cystine concentration. The tear strength also increases with the addition of Cystine. The elongation at break values shows a decrease as the Cystine concentration 
TABLE 2: Mechanicals properties of vulcanized NR.

\begin{tabular}{lccccc}
\hline Mix no. & $M 0$ & $M 1$ & $M 2$ & $M 3$ & $M 4$ \\
\hline $\begin{array}{l}\text { Elongation at break } \\
(\%)\end{array}$ & 913 & 883 & 827 & 843 & 803 \\
$\begin{array}{l}\text { Tensile strength } \\
(\mathrm{MPa})\end{array}$ & 13.93 & 17.30 & 27.92 & 25.63 & 24.61 \\
$\begin{array}{l}\text { Tear strength (N/mm) } \\
\text { Resilience (\%) }\end{array}$ & 17.97 & 25.33 & 24.83 & 24.97 & 27.11 \\
$\begin{array}{l}\text { Hardness (Shore A) } \\
\begin{array}{l}\text { Modulus (300\%) } \\
(\mathrm{MPa})\end{array}\end{array}$ & 30 & 35 & 38 & 39 & 36 \\
\hline
\end{tabular}

increases. This may be assigned to the decrease in flexibility resulting from the increase in crosslink density.

The modulus values at 300\% elongation are also given in Table 2. It is found that as the dosage of Cystine increases, the maximum modulus values also increase. The maximum modulus is shown by mix $M 2$.

This result indicates that a concentration of $0.5 \mathrm{phr}$ is possibly the optimum for the vulcanization system. This could be correlated with the observed crosslink density of the vulcanizate.

3.2. Rheological Characteristics. The only variable in the mixes is the concentration of Cystine. The minimum torque in the rheographs can be taken as a measure of the viscosity of the masticated rubber.

As the concentration of Cystine increases, the time needed for optimum cure $\left(t_{90}\right)$ decreases significantly. The decrease in cure time is extremely beneficial because it increases the production rate. However, the scorch time $\left(t_{\mathrm{sc}}\right)$ is found to be decreasing. This, in fact, affects the scorch safety of the compound. The cure characteristics are given in Table 3. The maximum torque, which is a measure of the stiffness of the compound, is found to increase with the Cystine concentration. It is directly related to the modulus of the compound. The cure activating nature of Cystine is evident from the processing characteristics of the vulcanizate.

3.3. Kinetic Studies. The cure rate index (CRI) value, which was a measure of the rate of the vulcanization process, increases significantly with the Cystine amount. CRI, kinetic parameter of vulcanization, was estimated according to the method reported by Menon et al. [13]

$$
\mathrm{CRI}=\frac{100}{\left(t_{90}-t_{\mathrm{sc}}\right)} \text {. }
$$

This emphasizes the cure activating nature of the secondary accelerator Cystine. A more standard treatment of this effect can be ensured by studying the kinetics of vulcanization using the method reported by Fujimoto et al. [14]. The general equation for the kinetics of a first-order chemical reaction can be written as

$$
\ln (c-x)=k t+\ln c .
$$

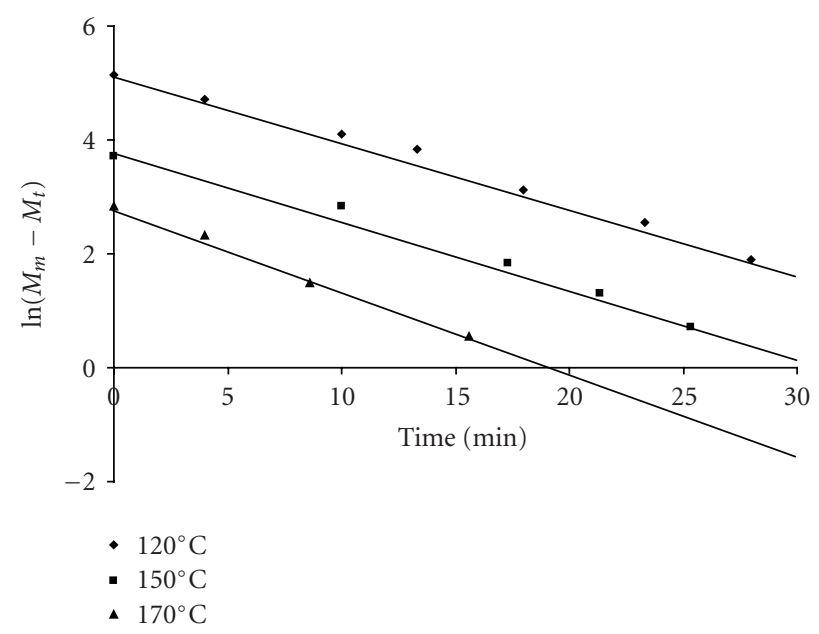

Figure 1: Plots of $\ln \left(M_{m}-M_{t}\right)$ versus time for mix $M 2$ at different temperatures.

Respectively, $c$ is the initial reactant concentration, $x$ is the reacted quantity of reactant at time $t$, and $k$ is the first-order rate constant. For the vulcanization reaction of natural rubber (NR), the rate of crosslink formation is usually monitored by measuring the torque developed during vulcanization. The torque values thus obtained are proportional to the modulus of the rubber. Because modulus and torque are analogous, we can substitute the torque value for the modulus

$$
\begin{gathered}
(c-x)=M_{m}-M_{t}, \\
c=M_{m}-M_{n} .
\end{gathered}
$$

Respectively, $M_{m}, M_{n}$, and $M_{t}$ are the maximum torque, minimum torque, and torque at time $t$, respectively. When in $\left(M_{m}-M_{t}\right)$ is plotted against $t$, a straight line graph is obtained as shown in Figure 1, which proves that the cure reaction of the compounds follows first-order kinetics. Even though linearity is claimed for the plots theoretically, deviations from linearity are experimentally observed for certain points. The observed linearity in the plots confirms that the cure reaction of the samples follow first-order kinetics. It is also clear form Figure 1 that a change in temperature does not affect the kinetic order of the vulcanization reaction. Regardless of the temperature and concentration of Cystine, all vulcanization reactions proceed according to first-order kinetics. The cure reaction $k$ values are obtained from the slope of the respective straight lines. The $k$ values and the CRI values for mixes are given in Table 4 . These values increase with temperature.

The Arrhenius equation was used to calculate the activation energy of the mixes

$$
\begin{gathered}
\left(t_{90}\right)^{-1}=C e^{-E / R T} \\
-\left(\log t_{90}\right)=\log C-\frac{E}{(2.303 R T)} .
\end{gathered}
$$


TABle 3: Cure characteristics of mixes at $150^{\circ} \mathrm{C}$.

\begin{tabular}{|c|c|c|c|c|c|}
\hline Mix no. & M0 & M1 & M2 & M3 & M4 \\
\hline Scorch Time (min) & 16.21 & 3.87 & 2.37 & 2.03 & 1.33 \\
\hline Optimal cure time (min) & 27.03 & 12.23 & 9.32 & 8.12 & 8.63 \\
\hline Torque max (d.Nm) & 43.63 & 54.54 & 56.36 & 57.63 & 58.18 \\
\hline Torque min (d.Nm) & 5.45 & 7.27 & 8.45 & 8.90 & 9.09 \\
\hline
\end{tabular}

TABLE 4: Cure kinetics parameters of mixes.

\begin{tabular}{|c|c|c|c|c|c|}
\hline Mix no. & M0 & $M 1$ & M2 & M3 & M4 \\
\hline$k$ value at Temperature $\left(120^{\circ} \mathrm{C}\right)$ & 0.029 & 0.056 & 0.088 & 0.093 & 0.011 \\
\hline$k$ value at Temperature $\left(150^{\circ} \mathrm{C}\right)$ & 0.083 & 0.113 & 0.125 & 0.133 & 0.154 \\
\hline$k$ value at Temperature $\left(170^{\circ} \mathrm{C}\right)$ & 0.105 & 0.147 & 0.163 & 0.181 & 0.213 \\
\hline CRI $\left(\min ^{-1}\right)$ & 9.32 & 11.96 & 13.17 & 13.5 & 13.69 \\
\hline Energy of activation $E(\mathrm{~kJ} / \mathrm{mol})$ & 79 & 72 & 69 & 67 & 64 \\
\hline
\end{tabular}

TABLE 5: Crosslinking density of vulcanized natural rubber.

\begin{tabular}{lccccc}
\hline Mix no. & $M 0$ & $M 1$ & $M 2$ & $M 3$ & $M 4$ \\
\hline Crosslink density $\left(10^{-2}\right.$ mol. $\left.\mathrm{cm}^{-3}\right)$ & 2.623 & 2.801 & 2.878 & 2.893 & 2.903 \\
Swelling ratio & 4.83 & 4.43 & 4.1 & 3.93 & 3.89 \\
\hline
\end{tabular}

Table 6: Double-Factors experiment plan $\left(2^{2}\right)$, typical data.

\begin{tabular}{lcccccc}
\hline & $B$ & Observations & Totals & Averages & Estimation & $Y_{1 . e}$ \\
\hline 1 & 1 & $Y_{1,1,1} Y_{1,1,2} \ldots Y_{1,1, n}$ & $Y_{1 .}$ & $\bar{Y}_{1}$ & $Y_{2 . e}$ & $\bar{Y}_{1}-Y_{1 . e}$ \\
2 & 2 & $Y_{2,2,1} Y_{2,2,2} \ldots Y_{2,2, n}$ & $Y_{2 .}$ & $\bar{Y}_{2}$ & $Y_{1 . e}$ \\
$\ldots$ & $\ldots$ & $\ldots \ldots \ldots \ldots$ & $\ldots$ & $\ldots$ & $\ldots$ & $\ldots$ \\
$a$ & $b$ & $Y_{a, b, 1} Y_{a, b, 2} \ldots Y_{a, b, n}$ & $Y_{a, b .}$ & $\bar{Y}_{a, b}$ & $Y_{a, b, e}$ & $\bar{Y}_{a, b}-Y_{a, b, e}$ \\
\hline
\end{tabular}

$a$ : number of different levels of factor $A$;

$b$ : number of different levels of factor $B$;

$n$ : numberof observations;

$Y_{1 .}=Y_{1,1,1}+Y_{1,1,2}+\cdots+Y_{1,1, n}$

$\bar{Y}_{1}=Y_{1 .} / n I=\left(\bar{Y}_{1}+\bar{Y}_{2}+\cdots+\bar{Y}_{a, b}\right) / a$.

TABLe 7: Experiment plan $\left(2^{2}\right)$-data.

\begin{tabular}{cccccccc}
\hline $\mathbf{N}^{\circ}$ & $A$ & $B$ & $A B$ & Totals & Average & Estimation & Residue \\
\hline 1 & -1 & -1 & 1 & 111.32 & 27.83 & 26.78 & 2.05 \\
2 & -1 & 1 & -1 & 108.40 & 27.10 & 28.15 & -1.05 \\
3 & 1 & -1 & -1 & 86.16 & 21.54 & 22.59 & -1.05 \\
4 & 1 & 1 & 1 & 100.08 & 25.02 & 23.97 & 1.05 \\
\hline
\end{tabular}

TABle 8: Experiment plan $\left(3^{3}\right)$-data.

\begin{tabular}{cccccccccc}
\hline $\mathrm{N}^{\circ}$ & $A$ & $B$ & $C$ & $A B$ & $Y_{1}$ & $Y_{2}$ & $Y_{3}$ & Totals & Average \\
\hline 1 & -1 & -1 & -1 & 1 & 26.91 & 26.79 & 26.95 & 80.65 \\
2 & -1 & 0 & 1 & 0 & 18.50 & 18.70 & 18.32 & 55.52 \\
3 & -1 & 1 & 0 & -1 & 27.20 & 27.10 & 27.30 & 81.60 \\
4 & 0 & -1 & 1 & 0 & 19.10 & 18.98 & 19.05 & 57.13 & 27.88 \\
5 & 0 & 0 & 0 & 0 & 27.90 & 27.94 & 27.92 & 83.76 \\
6 & 0 & 1 & -1 & 0 & 27.96 & 28.10 & 28.03 & 84.09 & 27.92 \\
7 & 1 & -1 & 0 & -1 & 21.52 & 21.54 & 21.56 & 64.62 & 28.03 \\
8 & 1 & 0 & -1 & 0 & 25.72 & 25.66 & 25.50 & 76.88 & 21.54 \\
9 & 1 & 1 & 1 & 1 & 24.85 & 24.88 & 24.91 & 74.64 & 25.62 \\
\hline
\end{tabular}


Table 9: Averages matrix for factors $A$ and $B$.

\begin{tabular}{cccccc}
\hline & & \multicolumn{4}{c}{$B$} \\
& & 1 & 2 & 3 & Averages \\
\hline \multirow{4}{*}{$A$} & 1 & 26.88 & 18.50 & 27.20 & 24.19 \\
& 2 & 19.04 & 27.92 & 28.03 & 24.99 \\
& 3 & 21.54 & 25.62 & 24.88 & 24.01 \\
& Averages & 22.48 & 24.01 & 26.70 & 24.40 \\
\hline
\end{tabular}

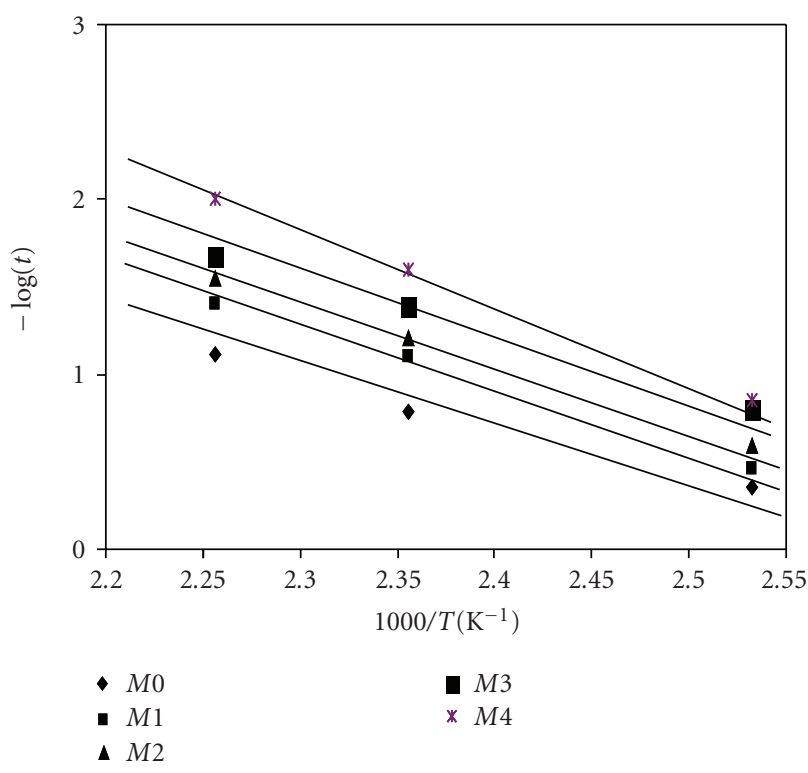

FIgUre 2: Arrhenius plots curing natural rubber.

A plot of $-\log t_{90}$ versus $1000 / T$ gives a straight line for all the mixes (Figure 2). The activation energy $(E)$ can be calculated from the slope of this line. The activation energies of the cure reactions are also given in Table 4. It is noteworthy to mention that the activation energy required for mix $M 0$ is the highest. In fact, this reaction requires much more energy and therefore will start and proceed slowly. The lower the activation energy is, the faster the cure reaction will be. The activation energy was the greatest for $M 0$. It is clear that the activation energy decreases with increasing concentration of Cystine, indicating faster initiation of the cure reaction.

3.4. Crosslink Density Measurements. Table 5 gives crosslinking density value measured by the equilibrium swelling method. The crosslinking density was found to increase with increasing secondary accelerator loading.

The physically effective crosslink density contains a contribution from the chemical crosslinks, chain entanglements and loose chain ends acting as crosslinks in the rubber $[15,16]$.

The effect of crosslinking is the most important and best understood in elastomers. Sulfur crosslinking of natural rubber produces a variety of crosslinking types and crosslink length [12]. Networks containing high proportions of polysulfidic crosslinks display mechanical properties that are different from those containing monosulfidic. It was

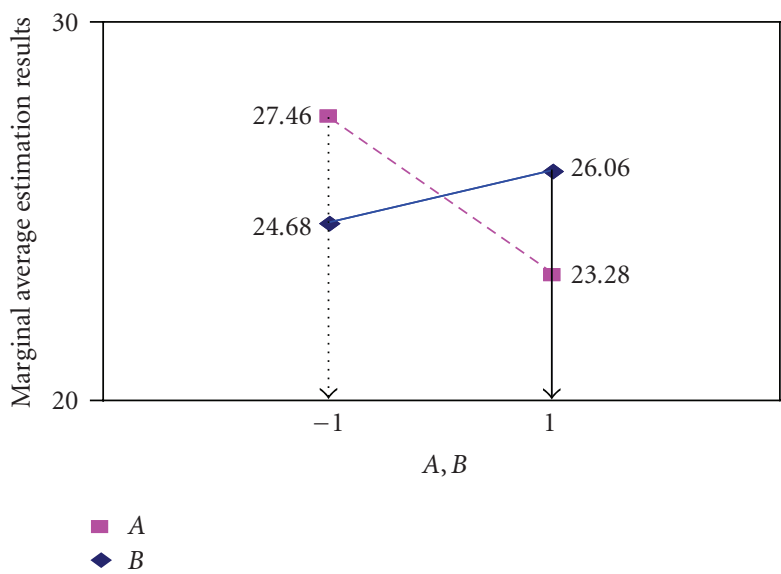

Figure 3: Interaction $A B$ (Cys, CBS).

shown in the literature [17] that rubbery tensile modulus is dependent on the crosslink density but almost independent from the crosslink type.

According to Table 5, the crosslink density is improved with Cystine. The advantageous concentrations obtained for the new binary accelerator are explained by the amount of crosslink density. It is seen from the mechanical behaviour that as the concentration of Cystine is increased from 0.5 to $1 \mathrm{phr}$, a slight decrease in tensile strength is observed, even if the crosslink density shows an increase. This could be assigned to the desulfuration process taking place. As the accelerator concentration is increased, polysulfidic linkages get converted to mono- and disulfidic linkages decrease. This type of behaviour is also observed in the modulus.

\subsection{Numerical Analysis of Interaction between New Binary} Accelerators. The numerical analysis of interaction is applied for evaluation of the effect of Cystine and CBS in the NR compositions. Tensile strength is considered as a function $Y$; $\{Y=F$ (Cys, CBS) $\}$, of binary accelerator concentration in the NR compositions and the range of (Cys, CBS) concentration of practical interest is fixed: range of Cys $($ minimum value $=0.4 \mathrm{phr}$, maximum value $=0.6 \mathrm{phr})$; range of CBS (minimum value $=0.7 \mathrm{phr}$, maximum value $=$ $0.9 \mathrm{phr})$.

Two levels for each Cystine concentration (factor $A$ ) and CBS concentration (factor $B$ ) are investigated.

Coded transformation [18] is used for each different level of factors $\mathrm{A}$ and $\mathrm{B}$. The range of factor $A$ is $[-1,1]$, and the range of factor $B$ is also $[-1,1]$.

Four test specimens at each concentration level are used in this investigation. All the sixteen specimens are tested in random order and the data from these experiments are organized according to Tables 6 and 7 [19-21]

$$
Y_{a, b, e}=I+\left(\alpha_{1} \alpha_{1} \cdots \alpha_{a}\right) A+\left(\beta_{1} \beta_{2} \cdots \beta_{b}\right) .
$$

Residue $=\bar{Y}_{a, b}-Y_{a, b, e} ; \quad \sum$ residue $=0$.

$\left(\alpha_{i}\right)$ : effect of factor $A$ at level $i ; \alpha_{i}=$ (average value result of factor $A$ at level $i$ ) $-I$, 
TABle 10: Matrix for interaction-terms of factors $A, B, C$, and $A B$.

\begin{tabular}{|c|c|c|c|c|c|}
\hline & & \multicolumn{4}{|c|}{$B$} \\
\hline & & & $\beta_{1}=-1.92$ & $\beta_{2}=-0.39$ & $\beta_{3}=2.31$ \\
\hline & & & -1 & 0 & 1 \\
\hline \multirow{3}{*}{$A$} & $\alpha_{1}=-0.21$ & -1 & $\alpha \beta_{1,1}=4.60$ & $\alpha \beta_{1,2}=-5.30$ & $\alpha \beta_{1,3}=0.70$ \\
\hline & $\alpha_{2}=0.60$ & 0 & $\alpha \beta_{2,1}=-4.03$ & $\alpha \beta_{2,2}=3.31$ & $\alpha \beta_{2,3}=0.72$ \\
\hline & $\alpha_{3}=-0.39$ & 1 & $\alpha \beta_{3,1}=-0.56$ & $\alpha \beta_{3,2}=2.00$ & $\alpha \beta_{3,3}=-1.44$ \\
\hline$C$ & -1 & 1 & $\gamma_{1}=2.44$ & $\gamma_{2}=1.15$ & $\gamma_{3}=-3.59$ \\
\hline
\end{tabular}

$\left(\beta_{j}\right)$ : effect of factor $\mathrm{B}$ at level $j ; \beta_{j}=$ (average value result of factor $B$ at level $j$ ) $-I$,

$$
\alpha \beta_{i, j}=Y_{i, j}-I-\alpha_{i}-\beta_{i} ; \quad i=\{1,2,3\}, j=\{1,2,3\} .
$$

According to Table 7 , the model of estimated result $\left(Y_{a, b, e}\right)$ as function of factor $A$ and $B$ was

$$
\begin{aligned}
Y_{a, b, e}= & 25.37+(+2.1-2.1)(A)+(-0.68+0.68)(B) \\
& \text { level }-1 \text { level } 1 \text { level }-1 \text { level } 1 .
\end{aligned}
$$

According to Figure 3, the interaction $A B$ seems to be significant, the lines cross for $A=-1$; results 27.83 and 27.10; for $A=+1$, results 21.54 and 25.02.

3.6. Operational Modelling with Interaction for an Experiment Plan $\left(3^{3}\right)$. The operational modelling [18] with interaction is applied for the optimisation of the dosage of the vulcanisation system (Cys, CBS, Sulfur) in the NR compositions. Tensile strength is considered as a function of Cys (factor $A$ ), CBS (factor $B$ ), and sulphur concentration (factor $C$ ) in the natural rubber compositions. The range of each compound is fixed at three levels: Cys (minimum value = $0.4 \mathrm{phr}$, middle value $=0.5 \mathrm{phr}$, maximum value $=0.6 \mathrm{phr}$ ); range of CBS (minimum value $=0.7 \mathrm{phr}$, middle value $=$ $0.8 \mathrm{phr}$, maximum value $=0.9 \mathrm{phr}$ ), and range of sulphur $\mathrm{S}$ ( minimum value $=2.3 \mathrm{phr}$, middle value $=2.5 \mathrm{phr}$, maximum value $=2.7 \mathrm{phr}$ ).

Coded transformation is also used for each different level of factors $A, B$, and $C$. The range of factor $A$ is $[-1,0,1]$, the range of factor $B$ is also $[-1,0,1]$, and the range of factor $C$ is $[-1,0,1]$. Three test specimens at each concentration level are used in this investigation. All the twenty seven specimens are tested in a random order and the data of these experiments are organized according to Table 8 .

The formula of modeling according to Table 8, which takes in account the interaction between binary accelerators, is

$$
\begin{aligned}
Y_{a, b, c, a b, e}= & +(\alpha 1 \alpha 2 \alpha 3)(A)+(\beta 1 \beta 2 \beta 3)(B) \\
& +(\gamma 1 \gamma 2 \gamma 3)(C)+\left[\begin{array}{ccc}
\alpha \beta_{11} & \alpha \beta_{12} & \alpha \beta_{13} \\
\alpha \beta_{21} & \alpha \beta_{22} & \alpha \beta_{23} \\
\alpha \beta_{21} & \alpha \beta_{32} & \alpha \beta_{33}
\end{array}\right] \times(A B) .
\end{aligned}
$$

$I$ : represents total average value of results; $I=24,40,\left(\alpha_{i}\right)$ : effect of factor $A$ at level $i ; \alpha_{i}=$ (average value result of factor
$A$ at level $i)-I,\left(\beta_{i}\right)$ : effect of factor $B$ at level $i ; \beta_{i}=$ (average value result of factor $B$ at level $i)-I,\left(\gamma_{i}\right)$ : effect of factor $C$ at level $i ; \gamma_{i}=$ (average value result of factor $C$ at level $\left.i\right)-I$, $\left(\alpha \beta_{i, j}\right)$ : corrective terms of the interaction between the two factors $A$ and $B$ (Table 9).

According to Table 10, the model of estimated results $\left(Y_{a, b, c, a b, e}\right)$ as function of factors $A, B, C$ and interaction $A B$ is

$$
\begin{aligned}
Y_{a, b, c, a b, e}= & 24.40+(-0.21+0.60-0.39)(A) \\
& +(-1.92-0.39+2.31)(B) \\
& +(+2.44+1.15-3.59)(C) \\
& +\left[\begin{array}{rrr}
+4.60 & -5.30+0.70 \\
-4.03 & +3.31+0.72 \\
-0.56 & +2.00 & -1.44
\end{array}\right](A B) .
\end{aligned}
$$

The numerical analysis preceding was the common form of test interaction of results described in investigation about utilization of binary compounds. The application of operational modelling is unusual and its use can bring more information about the optimum interaction effect of the new binary accelerator. So, the operational modelling is applied in the tensile strength results of natural rubber vulcanizate according to Table 10 . Table 10 summarizes the results that are found. It can be observed that tensile strength is affected by Cystine, and CBS concentration. According to the model (14) of estimated result, if the desired optimum value of tensile strength is maximum, factors $A, B$, and $C$ are suggested to be, respectively, at the levels $\mathbf{0},+\mathbf{1}$, and $-\mathbf{1}$. Based on the mechanical, rheological, network characteristics, and operational modelling, optimum concentration of $0.5 \mathrm{phr}$ for Cystine, $0.9 \mathrm{phr}$ for CBS, and $2.3 \mathrm{phr}$ for sulfur are recommended.

\section{Conclusions}

Based on this study, the following conclusions can be drawn.

(1) The mechanical properties of the vulcanizate were largely improved upon the addition of Cys.

(2) Effect was observed in the torque of the compound during vulcanization, because of the increased concentration of Cystine, which creates an augmentation in modulus.

(3) The above result shows that CRI and the rate constant values were effectively in excellent harmony. 
(4) Using the numerical analysis of interaction, operational modelling, mechanical properties, and kinetics of cure reaction of natural rubber vulcanizate cured with a new accelerator, it can be concluded, at a fine accord, that the addition of the new binary accelerator was found to increase the rate of vulcanization significantly.

\section{References}

[1] International Rubber Study Group, 2009, http://www .rubberstudy.com/economics-geninfo.aspx.

[2] W. Hofmann, Vulcanization and Vulcanizing Agents, Maclaren and Sons, London, UK, 1967.

[3] R. W. Layer, "A postcrosslinking accelerator system for natural rubber based on thiocarbamylsulfenamides," The Journal of Rubber Chemistry and Technology, vol. 60, no. 1, pp. 89-101, 1987.

[4] P. Das, R. Datta, and D. Basu, "Cure modification effected by cycloalkylthioamines in the vulcanization of NR," The Journal Rubber Chemistry and Technology, vol. 61, no. 5, pp. 760-782, 1988.

[5] A. S. Aprem, K. Joseph, and R. Laxminarayanan, "Physical, mechanical, and viscoelastic properties of natural rubber vulcanizates," The Journal of Applied Polymer Science, vol. 87, no. 14, pp. 2193-2203, 2003.

[6] F. Apruzzese, E. Bottari, and M. R. Festa, "Complex formation between cystine and alkali-metal cations," The Journal of Solution Chemistry, vol. 32, no. 1, pp. 65-76, 2003.

[7] M. Kamoun and M. Jaziri, "Physical, and mechanical properties of styrene butadiene rubber cured with new activator," Conference Report. Tn.Japan Symposium on Science Society and Technology eo37, 2006.

[8] D. L. Tsalev, A. D’Ulivo, L. Lampugnani, M. D. Marco, and R. Zamboni, "Thermally stabilized iridium on an integrated, carbide-coated platform as a permanent modifier for hydrideforming elements in electrothermal atomic absorption spectrometry part 3. effect of L-cysteine," The Journal of Analytical Atomic Spectrometry, vol. 11, no. 10, pp. 989-995, 1996.

[9] K. Suchiva, T. Kowitteerawut, and L. Srichantamit, "Structure properties of purified natural rubber," The Journal of Applied Polymer Science, vol. 78, no. 8, pp. 1495-1504, 2000.

[10] R. Joseph, K. E. George, and J. D. Francis, "Studies on the cure characteristics and vulcanizate properties of 50/50 NR/SBR blend," The Journal of Applied Polymer Science, vol. 35, no. 4, pp. 1003-1017, 1988.

[11] P. J. Flory and J. Rehner Jr., "Crosslink density equation," The Journal of Chemicals and Physics, vol. 11, p. 5120, 1943.

[12] A. S. Aprem, K. Joseph, and S. Thomas, "Studies on double networks in natural rubber vulcanizates," The Journal of Applied Polymer Science, vol. 91, no. 2, pp. 1068-1076, 2004.

[13] A. R. R. Menon, C. K. S. Pillai, and G. B. Nando, "Vulcanization of natural rubber modified with cashew nut shell liquid and its phosphorylated derivative-a comparative study," Science, vol. 39, no. 17, pp. 4033-4036, 1998.

[14] K. Fujimoto, T. Nishi, and T. Okamoto, "Devulcanization of NB based latex products for tyre applications," The International Journal of Polymer Science and Technology, vol. 8, no. 8, pp. 29-30, 1981.

[15] R. S. Rivlin, “The elasticity of rubberx," The Journal of Rubber Chemical Technology, vol. 65, no. 3, p. 51, 1992.
[16] D. S. Campbell and A.V. Chapman, "Natural rubber research," The Journal of Natural Rubber Research, vol. 5, no. 4, pp. 246258, 1990.

[17] R. Hagen, L. Salmen, and B. Stenberg, "Effects of the type of crosslink on viscoelastic properties of natural rubber," The Journal of Polymer Science B, vol. 34, no. 12, pp. 1997-2006, 1996.

[18] G. Lasnier, "Plans d'experiences en gestion industrielle," Hermes Sciences Publication, vol. 1, no. 57639, pp. 15-79, 2003.

[19] C. Lewis, R. Buanpa, and S. Kiatkamjornwong, "Effect of rubber ratio, carbon black level, and accelerator level on natural rubber/bromobutyl rubber blend properties," The Journal of Applied Polymer Science, vol. 90, no. 11, pp. 30593068, 2003.

[20] C. H. Chen and Y. W. Lo, "Application of factorial experimental design to demonstrate the influence of processing conditions on the fusion of poly(vinylchloride)/chlorinated polyethylene/oxidized polyethylene blends," The Journal of Applied Polymer Science, vol. 73, no. 13, pp. 2755-2761, 1999.

[21] C. M. P. Bizi and N. R. Demarquette, "Effect of the processing conditions and the addition of trans-polyoctenylene rubber on the properties of natural rubber/styrene-butadiene rubber blends," The Journal of Applied Polymer Science, vol. 109, no. 1, pp. 445-451, 2008. 

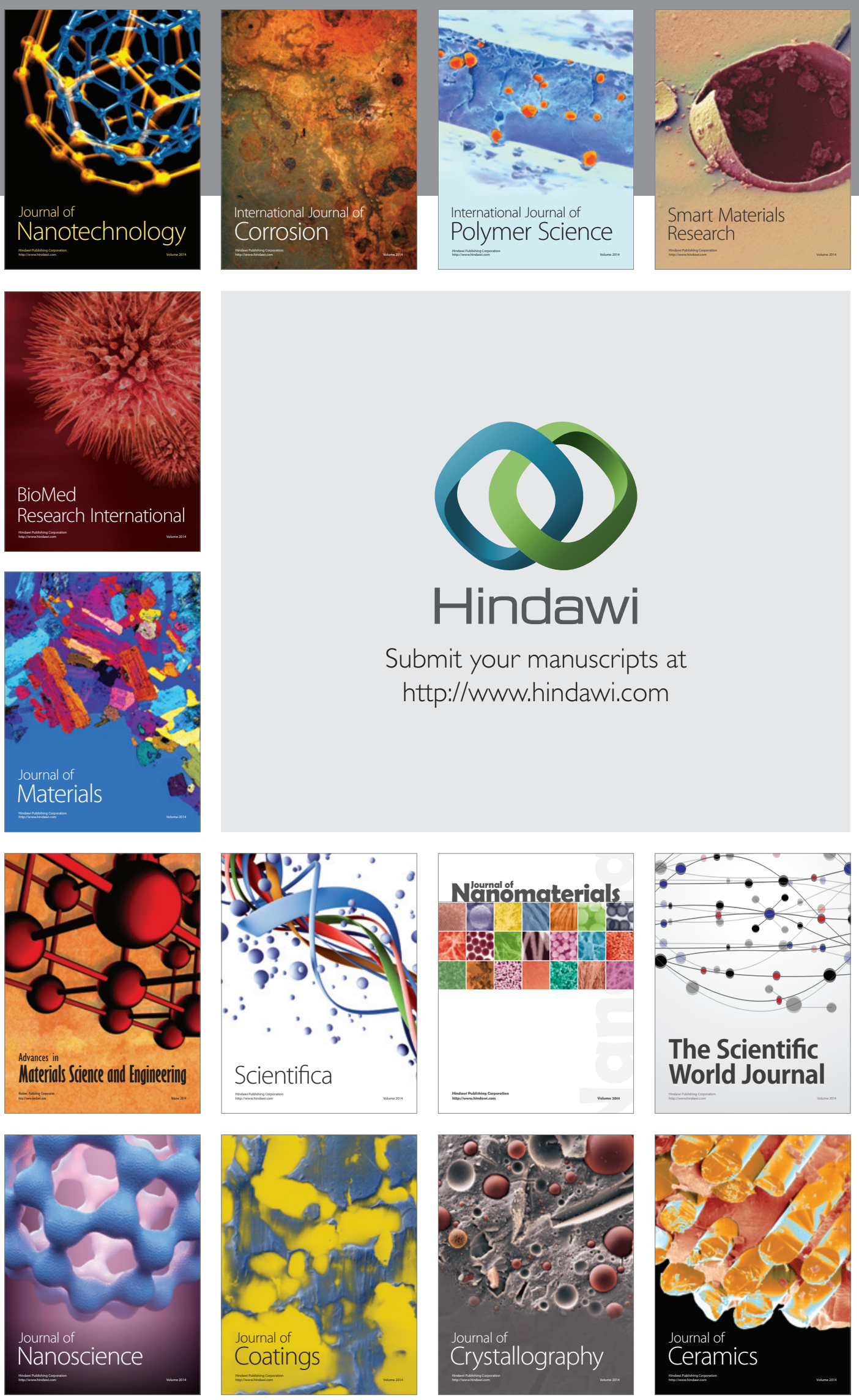

The Scientific World Journal

Submit your manuscripts at

http://www.hindawi.com

\section{World Journal}

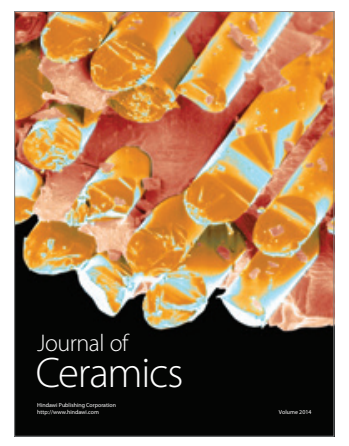

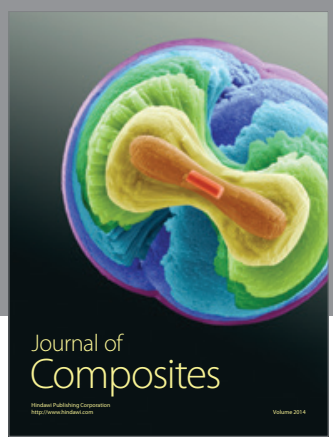
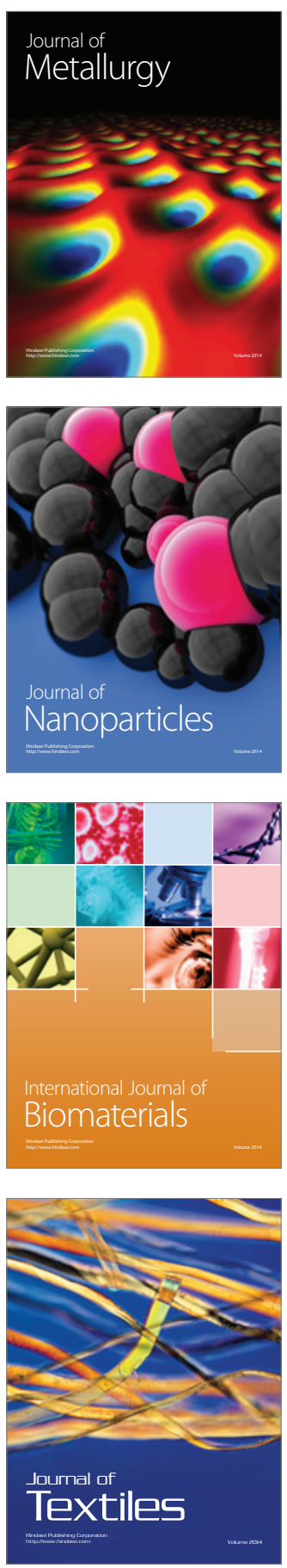